\title{
Call for Submissions: Special Issue, Cultural and Pedagogical Inquiry (CPI)
}

Fall 2019

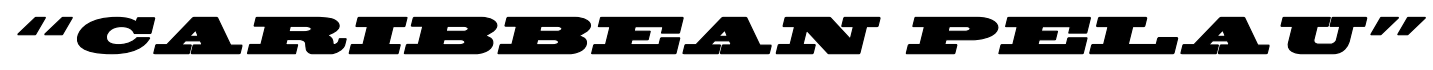

This Special Issue of Cultural and Pedagogical Inquiry (for publication in Fall 2019), concentrates on Caribbean voices. It throws into sharp focus tertiary educational institutions in the region, and highlights their global impacts and diasporic influences. The Guest Editors welcome creative approaches which speak to evolving Caribbean contents, contexts, personalities and identities, cultures and inimitable styles, all are depicted vividly, in order to explore the importance of the arts and culture in education.

"Caribbean Pelau" will showcase new directions of the visual and performing arts in the Caribbean region. The thought provoking and inspirational works will speak to cultural infusion... a melange of sometimes exotic, often explosive flavours, rich legacies from our multiracial and multi-ethnic heritages. In symbolic terms include some curry and jerk flavors. Let's produce an issue which continues to show the world our strengths!

Potential authors, poets, visual artists, choreographers, composers who are interested in contributing to this CPI Special Issue, please submit a proposal in either a single Word or PDF file to either of the Co-Editors listed below, by December 15, 2018. Since CPI is an online journal, photographs, film, video, performance, sound, and text (scripts, poetry, essays, articles), can be included.

Your proposal will include:

- A title (up to 150 characters).

- An abstract (100 -150 words).

- A description of the text/music/performance (400 words). If applicable:

- Visual images (photography, painting, sculpture, fibre/fabric, design, etc.).

- Visual artists also submit an artist statement.

Carol Campbell: revolutiongallery.jm@gmail.com or c.campbell@emc.edu.jm Jeanette Campbell: 1.jeanette.campbell@emc.edu.jm 